\title{
Vertical structure of the lower troposphere derived from MU radar, unmanned aerial vehicle, and balloon measurements during ShUREX 2015
}

Hubert Luce ${ }^{1}$, Lakshmi Kantha², Hiroyuki Hashiguchi ${ }^{3^{*}} \mathbb{D}$, Dale Lawrence ${ }^{2}$, Tyler Mixa² ${ }^{2}$ Masanori Yabuki and Toshitaka Tsuda ${ }^{3}$

\begin{abstract}
The ShUREX (Shigaraki UAV Radar Experiment) 2015 campaign carried out at the Shigaraki Middle and Upper atmosphere (MU) observatory (Japan) in June 2015 provided a unique opportunity to compare vertical profiles of atmospheric parameters estimated from unmanned aerial vehicle (UAV), balloon, and radar data in the lower troposphere. The present work is intended primarily as a demonstration of the potential offered by combination of these three instruments for studying the small-scale structure and dynamics in the lower troposphere. Here, we focus on data collected almost simultaneously by two instrumented UAVs and two meteorological balloons, near the MU radar operated continuously during the campaign. The UAVs flew along helical ascending and descending paths at a nearly constant horizontal distance from the radar $(\sim 1.0 \mathrm{~km})$, while the balloons launched from the MU radar site drifted up to $\sim 3-5 \mathrm{~km}$ in the altitude range of comparisons ( 0.5 to $4.0 \mathrm{~km})$ due to wind advection. Vertical profiles of squared Brünt-Väisälä frequency $N^{2}$ and squared vertical gradient of generalized potential refractive index $M^{2}$ were estimated at a vertical resolution of $20 \mathrm{~m}$ from pressure, temperature, and humidity data collected by UAVs and radiosondes. Profiles of $M^{2}$ were also estimated from MU radar echo power at vertical incidence at a vertical sampling of $20 \mathrm{~m}$ and various time resolutions (1-4 min). The balloons and the MU radar provided vertical profiles of wind and wind shear $S$ so that two independent estimates of the gradient Richardson number $\left(R i=N^{2} / S^{2}\right)$ could be obtained at a range resolution of $150 \mathrm{~m}$. The two estimates of Ri profiles also showed remarkable agreement at all altitudes. We show that all three instruments detected the same prominent temperature and humidity gradients, down to decameter scales in stratified conditions. These gradients extended horizontally over a few kilometers at least and persisted for hours without significant changes, indicating that the turbulent diffusion was weak. Large discrepancies between $N^{2}$ and $M^{2}$ profiles derived from the balloon, UAV, and radar data were found in a turbulent layer generated by a Kelvin-Helmholtz $(\mathrm{KH})$ shear flow instability in the height range from 1.80 to $2.15 \mathrm{~km}$. The cause of these discrepancies appears to depend on the stage of the KH billows.
\end{abstract}

Keywords: MU radar, Unmanned aerial vehicle (UAV), Lower troposphere and boundary layer, Refractive index gradient, Kelvin-Helmholtz instability, Temperature and moisture fine structures, Sheets and layers, Gradient Richardson number

\footnotetext{
* Correspondence: hasiguti@rish.kyoto-u.ac.jp

${ }^{3}$ Department of Aerospace Engineering Sciences, University of Colorado

Boulder, Boulder, CO, USA

Full list of author information is available at the end of the article
} 


\section{Introduction}

Nearly co-located and simultaneous measurements from instrumented Unmanned Aerial Vehicles (UAV) (Lawrence and Balsley 2013), balloon-borne radiosondes, and the $46.5 \mathrm{MHz}$ middle and upper atmosphere (MU) radar were made for the first time at the Shigaraki MU observatory during the ShUREX (Shigaraki UAV Radar Experiment) campaign in June 2015. Kantha et al. (2017) describe the experimental set up and present preliminary results for illustrating the potential of the collected datasets. Luce et al. (2018) took advantage of the UAV echoes in the MU radar Doppler spectra for an ultimate validation and evaluation of a frequency domain interferometry technique used to improve the range resolution of the radar. Luce et al. (2017) compared profiles of the squared generalized potential refractive index gradient $M^{2}$ (Ottersten 1969) derived from pressure, temperature, and humidity (PTU) data collected by the UAVs with those derived from MU radar echo power by using a model based on partial reflection mechanism. They concluded that the MU radar provides faithful highresolution profiles of the vertical temperature and humidity gradients down to decameter scale, at a time resolution of only a few tens of seconds, in at least stratified and clear air conditions. Their study confirmed the qualitative results obtained by Luce et al. (2010) from comparisons with simultaneous and co-located lidar measurements of humidity profiles.

In the present work, additional comparisons of atmospheric parameters are presented by including balloon data not presented in Luce et al. (2017). The balloons were launched at the MU radar observatory site almost simultaneously to the flights of two UAVs, at a time interval of about $2 \mathrm{~h}$ on 07 June 2015. The concurrent use of all three instruments enabled us to make comparisons between independent estimates of various atmospheric parameters: squared Brünt-Väisälä frequency $N^{2}$, squared generalized potential refractive index gradient $M^{2}$, horizontal wind $(V)$, and wind shear $\left(S=\sqrt{(d u / d z)^{2}+(d v / d z)^{2}}\right)$, where $u$ and $v$ are the zonal and meridional wind components, respectively, and the Richardson number $\left(R i=N^{2} / S^{2}\right)$. The definitions of $N^{2}$ and $M^{2}$ are given in Appendix 'Definition and estimation of $N^{2}$ and $M^{2}$ ' section. For clarity and simplicity, Table 1 assembles all possible combinations described in the present study. In addition to these combinations, comparisons between profiles estimated from UAV data during ascents and descents are also presented. In principle, it is possible to estimate horizontal winds from UAV data, but this possibility has yet not been realized.

It will be shown that UAV and balloon measurements provide virtually the same profiles of the atmospheric
Table 1 List of atmospheric parameters measured or calculated from UAV, balloon, and radar data (resolution of the profiles are given in meters)

\begin{tabular}{llll}
\hline & UAV & Balloon & MU radar \\
\hline PTU & $(\sim 2)$ & $(\sim 2-3)$ & \\
$N^{2}$ & $20,150^{a}$ & 20,150 & \\
$M^{2}$ & 20 & 20 & 20 \\
$V$ & & 20,150 & 150 \\
$S$ & & 20,150 & 150 \\
$R i=N^{2} / S^{2}$ & 20,150 & $150^{a}$ \\
\hline
\end{tabular}

${ }^{\mathrm{a}}$ The Richardson number was obtained from the wind shear measured by the MU radar and $N^{2}$ estimated from UAV data at a vertical resolution of $150 \mathrm{~m}$

parameters in stably stratified conditions above the altitude of $2.15 \mathrm{~km}$. These results are important for two reasons. On the one hand, they confirm that UAV measurements made from helical paths are as reliable as balloon measurements for profiling these atmospheric parameters down to decameter scale, at least, for the atmospheric conditions met during the observations. On the other hand, they suggest that this kind of comparisons can also provide additional insights into the characteristics of the thin layers of temperature and humidity gradients in the lower atmosphere. The existence of these gradients is well known, especially in the stable boundary layer and in the lower stratosphere. They can be even much thinner than those described here (e.g., Misme et al. 1958; Saxton et al. 1964; Du Castel 1966; Gossard et al. 1985; Dalaudier et al. 1994; Luce et al. 1995; Muschinski and Wode 1998). However, little is known about their characteristics, time evolution, and formation mechanisms because observations are still sparse and challenging (e.g., Fritts and Rastogi 1985; Luce et al. 2001a). A better knowledge of these characteristics is desirable because they can potentially affect all wave propagation (light, sound, radio waves) and can have an impact on the vertical transport of properties in stratified conditions. Owing to their flexibility of use, UAVs, in association with additional observations from radars, can contribute to this goal.

It will also be shown that the largest discrepancies between the profiles occurred below the height of $2.15 \mathrm{~km}$, where turbulence associated with convective clouds and Kelvin-Helmholtz shear instabilities was detected by the radar. The discrepancies in the $\mathrm{KH}$ turbulent layer could be partly due to the horizontal scale of $\mathrm{KH}$ billows, found to be of the order of, or even smaller than, the horizontal distance between the measurements made by the three instruments. The present work describes in detail, the characteristics of the various profiles in such conditions and complements the discussion presented by Luce et al. (2017) based on $M^{2}$ comparisons only. 
The layout of the paper is as follows. In the section "Experimental/Methods," instruments and datasets are first briefly described [see also Kantha et al. 2017] and a short outline of the methods used for deriving the atmospheric parameters from the different datasets is given among with references for more details. In the section "Results," time-height cross-sections of parameters measured by the MU radar are first analyzed in order to document the conditions met during the UAV/balloon flights. Then, the results of comparisons between profiles of atmospheric parameters are described. Discussions and concluding remarks are given in the section "Conclusions."

\section{Experimental/Methods Instruments and data MU radar}

The MU radar is a $46.5 \mathrm{MHz}$ beam-steering, Doppler pulsed radar located at Shigaraki MU Observatory $\left(34.85^{\circ} \mathrm{N}, 136.10^{\circ} \mathrm{E}\right)$ in Japan (Fukao et al. 1990). The radar parameters used during the campaign are listed in Table 2 . The range resolution defined by the transmitted pulse length was $150 \mathrm{~m}$, but a frequency domain interferometry technique, called range imaging, was applied in order to get an effective range resolution of the echo power profiles of a few tens of meters at vertical

Table 2 MU radar parameters used during ShUREX 2015 campaign

\begin{tabular}{ll}
\hline Parameter & \\
\hline Beam directions & $\left(0^{\circ}, 0^{\circ}\right),\left(0^{\circ}, 0^{\circ}\right),\left(0^{\circ}, 0^{\circ}\right),\left(0^{\circ}, 0^{\circ}\right),\left(0^{\circ}, 0^{\circ}\right)$, \\
& $\left(0^{\circ}, 10^{\circ}\right),\left(45^{\circ}, 10^{\circ}\right),\left(90^{\circ}, 10^{\circ}\right),\left(135^{\circ}, 10^{\circ}\right),\left(180^{\circ}, 10^{\circ}\right)$ \\
Radar frequencies $(\mathrm{MHz})$ & $46.00,46.25,46.50,46.75,47.00$ \\
Interpulse period $(\mu \mathrm{s})$ & 400 \\
Subpulse duration ( $\mu \mathrm{s})$ & 1 \\
Pulse coding & 116 -bit optimal code ${ }^{\mathrm{b}}$ \\
Range resolution (m) & 150 \\
Height sampling (FII) (m) & 5 \\
Number of gates & 128 \\
Coherent integration & 32 \\
number & \\
Incoherent integration & $-($ time series) \\
number & 128 \\
Number of FFT points & $16.384^{\mathrm{a}}$ \\
Acquisition time (s) & 4.096 \\
Time sampling (s) & 3.9063 \\
Nyquist frequency (Hz) & 12.6 \\
Velocity aliasing (ms $\left.{ }^{-1}\right)$ &
\end{tabular}

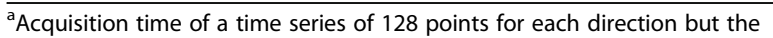
effective time resolution is about half $(\sim 8 \mathrm{~s})$ due to Hanning windowing of the time series. FIl, frequency domain radar interferometric imaging. FFT, fast Fourier transform

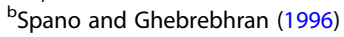

incidence (e.g., Luce et al. 2001b). The radar parameters were set up so that one high-resolution profile of echo power at vertical incidence was acquired from the altitude of 1.270 up to $20.465 \mathrm{~km}$ above the mean sea level (ASL) every $\sim 4 \mathrm{~s}$ at an effective time resolution of $\sim 8 \mathrm{~s}$ (see Table 2). In addition, five oblique beams steered at $10^{\circ}$ off zenith were included for estimating additional parameters at the same time resolution and at a range resolution of $150 \mathrm{~m}$. The radar measurements were interrupted every $\sim 35$ min for a few minutes for technical reasons.

\section{UAV}

Small (less than $1 \mathrm{~m}$ wingspan and about $700 \mathrm{~g}$ mass) UAVs equipped with autopilots were pre-programmed to execute a preplanned trajectory near the MU radar. They use GPS for navigation so that they could be operated precisely at given distances from the radar. Lawrence and Balsley (2013) and Balsley et al. (2013) describe the design of the UAVs, the characteristics of ground support components, and some data collected from these systems. Kantha et al. (2017) describe the specific characteristics of the UAVs during the ShUREX 2015 campaign.

The UAVs were equipped with various sensors for measurements of various atmospheric parameters. In particular, the sensors on the IMET radiosonde mounted on the UAV provided measurements of pressure, temperature, and relative humidity (PTU) at a sampling rate of $1 \mathrm{~Hz}$. The trajectories of the two flights described in the present work (hereafter, called UAV4 and UAV5 because they corresponded to the fourth and fifth flights of the campaign, respectively) were helical during ascent and descent over a spot located at a horizontal distance of about $1.0 \mathrm{~km}$ southwest of MU radar. The ascent and descent of UAV4 (UAV5) will be hereafter denoted UAV4A (UAV5A) and UAV4D (UAV5D), respectively. The diameter of helical patterns was $\sim 100$ to $150 \mathrm{~m}$, and the ascent (descent) rate of the UAVs was about $2 \mathrm{~ms}^{-1}$.

\section{Balloons}

Two meteorological balloons (hereafter called B1 and B2) equipped with Vaisala RS92G radiosondes were launched from the MU radar site. They mainly provided PTU, zonal, and meridional winds at a sampling rate of $1 \mathrm{~Hz}$. The balloons were underinflated so that they ascended virtually at the same velocity as the UAVs (i.e., $\sim 2 \mathrm{~ms}^{-1}$ ). They climbed to about the altitude of $4.0 \mathrm{~km}$ within an hour. B1 was launched almost at the same time as UAV4 and B2 was launched about $1 \mathrm{~h}$ after the take-off of UAV5. Table 3 shows the main characteristics of the UAV and balloon flights, and Fig. 1a, b shows their heights vs time (red curves, UAV; blue curves, balloons). 
Table 3 Brief description of the selected UAV flights (07 June 2015) and Vaisala radiosondes

\begin{tabular}{cll}
\hline UAV flight & Time $(\mathrm{LT})$ & Maximum height $(\mathrm{km})$ \\
UAV4 & 05: $44: 00$ & 3.9 \\
UAV5 & 07: 14: 11 & 4.3 \\
Balloon flight & Time (LT) & Maximum horizontal drift $(\mathrm{km})$ \\
B1 & 05: $53: 43$ & $\sim 3.3$ \\
B2 & 08: $12: 48$ & $\sim 5.2$ \\
\hline
\end{tabular}

Data processing methods

MU radar data

For each sampled altitude from $1.345 \mathrm{~km}$ above the sea level (ASL), echo power, Doppler velocity, spectral width, and signal to noise ratio (SNR) were estimated from Doppler spectra at vertical and oblique $\left(10^{\circ}\right.$ off zenith) incidences at a range resolution of $150 \mathrm{~m}$ using the moment method (e.g., Yamamoto et al. 1988). The vertical air velocity $W\left(\mathrm{~ms}^{-1}\right)$ was directly estimated from the Doppler shift at vertical incidence. By convention, a positive (negative) value of $W$ indicates upward (downward) motions. The zonal and meridional wind components $u$ and $v$ were obtained by combining the radial velocities in the different beam-pointing directions. The vertical shear of horizontal wind $S$ and the shear of horizontal wind speed (or "speed shear") $S_{V}=|d V / d z|$ were calculated from time-averaged (about $1 \mathrm{~h}$ ) profiles of $u, v$, and $V$, using a 3-point central scheme for the vertical derivatives.

The spectral width or variance of the Doppler spectra is partly due to clear air turbulence. The extraction of the variance $\sigma^{2}$ expected to be due to turbulence only was performed using the method described by Wilson et al. (2014). The details of the data processing are not given here, since $\sigma^{2}$ is simply used as an index of turbulence for the present purpose.

Aspect ratio AR of echo power is defined as the ratio between echo powers at vertical and oblique incidences, usually expressed in decibel. AR is a statistical parameter giving information about the anisotropy of the scatterers at the scale to which the radar is sensitive (i.e., half the radar wavelength) (e.g., Gage 1990). When close to $0 \mathrm{~dB}$, backscattering from isotropic turbulence should be dominant. When $A R$ is large (say $>10 \mathrm{~dB}$ ), echoes are believed to arise from stable gradient layers that are horizontally quasi-coherent. Here, AR was calculated as the difference (in decibel) between the vertical echo power and the average power measured by the five oblique beams.

Because the estimations of Doppler velocity and, to a greater extent, width of Doppler spectra are very sensitive to contaminations (e.g., ground clutter, airplane echoes, electromagnetic interferences), especially with the moment method, all the Doppler spectra obtained from the six beam directions were edited and carefully corrected manually by replacing contaminated portions of the spectra by an average noise level. The procedure was tedious but necessary, especially for removing the UAV echo contaminations. It was only possible when the UAV echo peak did not overlap the Doppler peak of atmospheric echoes. Overlapping could be avoided most of the time, owing the configuration of flight used but not always. In such cases, the data were discarded.

Vertical profiles of echo power $P_{\mathrm{MU}}$ at a range resolution of a few tens of meters were also obtained at vertical incidence owing to the application of a multiple frequency domain interferometry technique, called range imaging, with the adaptive filter-bank Capon processing method. Luce et al. (2001b) described the principle of the technique that became operational on the MU radar in 2004 after upgrades (Luce et al. 2006). Profiles of $M^{2}$ were estimated from $P_{\mathrm{MU}}$ at vertical incidence at a vertical sampling of $20 \mathrm{~m}$ using the theoretical derivations and practical methods already described by Luce et al. (2017). Basically, the $M^{2}$ profiles were estimated from the average of $P_{\mathrm{MU}}$ over 1 and $4 \mathrm{~min}$, along the time-height position of the UAVs (shown by the red lines in Fig. 1a, b).

\section{Balloon and UAV data}

PTU data gathered by the UAVs and balloons were used for estimating vertical profiles of $N^{2}$ and $M^{2}$ (Kantha et al. 2017; Luce et al. 2017). The PTU profiles were first resampled at a constant altitude step and smoothed at a vertical resolution of $20 \mathrm{~m}$ after applying a low-pass filter (cut-off $=40 \mathrm{~m}$ ). The same procedure was applied on the wind profiles collected by the radiosondes for estimating $\mathrm{S}, S_{V}$, and $R i$ from balloon data at vertical resolution of $20 \mathrm{~m}$. When comparing with the radar-derived profiles of $S$ and $S_{V}$ at range resolution of $150 \mathrm{~m}$, the zonal and meridional wind components measured by radiosondes were first low-pass filtered (cut-off $=300 \mathrm{~m}$ ) and resampled before calculating $S$ and $S_{V}$ at the same resolution of $150 \mathrm{~m}$.

\section{Results and discussions \\ Radar images \\ Radar echo power at high resolution}

Figure 1a, b shows time-height cross-sections of $P_{\mathrm{MU}}$ (decibel, arbitrary levels) at vertical incidence and in the height range $1.27-5.00 \mathrm{~km}$ during the flight period of UAV4/B1 and UAV5/B2, respectively. As shown by Luce et al. (2018), the radar continuously detected the echoes backscattered from the UAVs. The green curves showing distances of the UAVs to the radar antenna array estimated from the onboard GPS measurements perfectly overlap the UAV echo peaks, indicating a suitable 


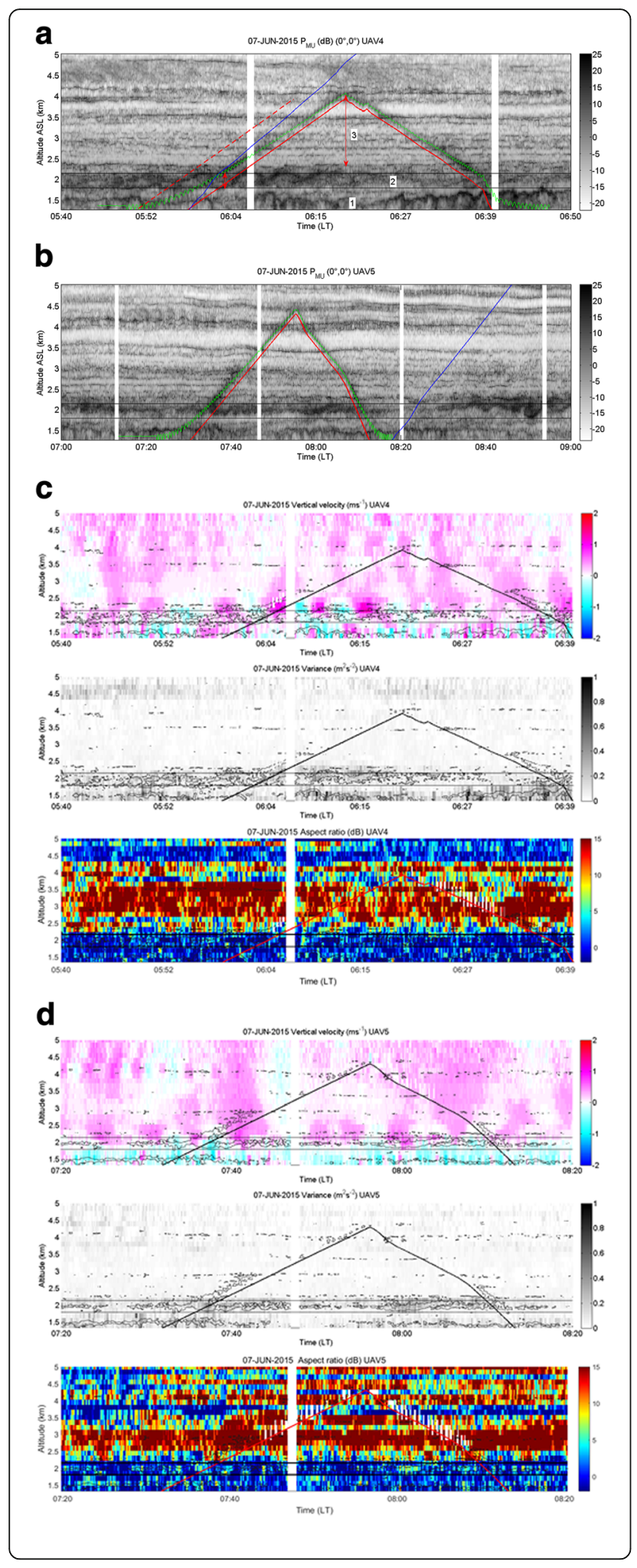

Fig. 1 a (Top) Time-height plot of MU radar echo power at vertical incidence and high-range resolution from 05:40 to 06:50 LT on 7 June 2015 corresponding to UAV4 and B1. The red (green) line shows the altitude (distance) of UAV4 vs. time. The blue line shows the altitude of B1 vs. time. The label 1 refers to cloud region, 2 to the $\mathrm{KH}$ region, and 3 to the stratified region, respectively. These 3 regions are separated by horizontal black lines at 1.80 and $2.15 \mathrm{~km}$, for clarity. See the text for more details. b As in Fig. 1,a but for UAV5 and B2. c (Top) Time-height plot of the vertical velocity measured by MU radar from 05:40 to 06:40 LT on 7 June 2015 during the flight of UAV4. (Center) The corresponding time-height plot of Doppler variance corrected for beam broadening measured at vertical incidence. (Bottom) Aspect ratio defined as the difference (in decibel) between the vertical echo power and the average of the five oblique echo powers. Superimposed are isolines of echo power (Fig. 1a) for $P_{\mathrm{MU}}=10 \mathrm{~dB}$ showing the edges of the $\mathrm{KH}$ braids and the top of the cloudy cells. The horizontal solid lines delineate the $\mathrm{KH}$ region (2). The black or red curves show the altitude of UAV4 vs time, as in Fig. 1.a. d As Fig. 1c, but for the radar observations during UAV5

calibration in altitude of the radar. The twisted appearance of the curves results from the helical motions of the UAVs. B1 was almost synchronized with UAV4A. Both instruments probed the same altitudes with a time lag of a few minutes only but with a horizontal separation of a few kilometers due to the balloon drift. Figure 2 shows the horizontal trajectories of B1 and B2 with respect to MU radar site, the UAV flight paths (nearly identical for UAV4 and UAV5), and additional information described later on.



Fig. 2 Horizontal trajectories of B1 (black line), B2 (gray line), and the UAVs (black circles at the bottom of the figure). The red (green) arrow shows the mean wind (shear) vector in the $\mathrm{KH}$ region (2) according to B1 data and scaled by 250 . The variations of the wind shear scaled by 25 in the $\mathrm{KH}$ region (2) are given by the short green arrows. The dashed lines show the expected billow crest axes assumed to be perpendicular to the wind shear direction 
Labels and horizontal black lines in Fig. 1a refer to altitude ranges (hereafter, called "regions") in which radar echoes exhibit distinct patterns. These regions were associated with different atmospheric states and dynamics according to UAV and balloon data analyses shown by Figs. 3, 4, and 5. These figures are now utilized as complement to the radar observations for their interpretations. The results of comparisons between the profiles will be described in the next section.

Label (1): A region in which an enhanced and irregular echo layer was embedded, corresponding to the top edges of convective cloud cells. The relative humidity data collected from UAV and balloon measurements confirm the presence of saturated air in that region (Fig. 3). The bumpy structures recall those observed by FMCW radars in convective boundary layers (e.g., Gossard 1990) and might be a signature of cumulus clouds. Entrainment of subsaturated air by the convective motions likely produced the enhanced echoes at the troughs of the cells. The altitude of the top edge was very irregular with time, from $\sim 1.3 \mathrm{~km}$ around 06:20 LT up to $\sim 1.8 \mathrm{~km}$ at 06:45 LT. Similar but less prominent structures were observed during UAV5 (Fig. 1b).

Label (2): An intense echo layer showing evidence of braided cat's-eye pattern believed to result from KelvinHelmholtz (KH) instability. The enhanced wind shear and the minimum of $R i$ in this region (Figs. 4 and 5 , respectively) are consistent with this interpretation. The KH instability topped the humid region (1) and occurred at the bottom of the temperature inversion that was probably affected itself by the $\mathrm{KH}$ instability (Fig. 3). During UAV4A, the crest-to-trough amplitude of the $\mathrm{KH}$ braids, indicated by the horizontal black lines, did not exceed $350 \mathrm{~m}$ between 1.80 and $2.15 \mathrm{~km}$. The $\mathrm{KH}$ braids were capped by a persistent and thin echo layer at the altitude of $\sim 2.45 \mathrm{~km}$ and by more or less well-defined enhanced echo layers between them (Fig. 1a, b). The KH braids faded away after 06:15 LT and were replaced by relatively indistinct echo power patterns. During UAV4D, KH breaking wave of smaller dimensions may have occurred just above $1.8 \mathrm{~km}$ between 06:35 and 06:40 LT. The enhanced echo layers around $2.0 \mathrm{~km}$ after B2 flight ( 08:30 LT) were also likely due to the $\mathrm{KH}$ instabilities but the billows appeared clearly only after 08:50 LT. B2 ascent was when radar echoes were significant weaker.

The depth of the region (2) was defined according to the morphology of the large amplitude $\mathrm{KH}$ braids before and during UAV4A. They do not necessarily fit their vertical extent at a later time, but the same ranges were delineated in Fig. 1b for an easier description.
Label (3): A region of persistent multi-layer fine structure characteristic of stratified conditions. Figure 3 shows that this region corresponded to much drier conditions compared to regions (1) and (2). It has been limited at the top by the maximum altitude of the UAVs. The thin echo layers were quite regularly spaced vertically without evidence of merging. They were quite stable in height during UAV4, but they showed vertical wave-like oscillations during UAV5.

\section{Additional radar observations}

Figure 1c, d shows time-height cross-sections of $W$ $\left(\mathrm{ms}^{-1}\right)$ (top panel), $\sigma^{2}\left(\mathrm{~m}^{2} \mathrm{~s}^{-2}\right)$ (middle panel), and AR (dB) (bottom panel) for the two periods shown in Fig. 1a, b, respectively.

In the cloudy region (1), the radar images show the following:

(a) W fluctuations (up to $+/-0.5 \mathrm{~ms}^{-1}$ ) with downward motions in the trough of the convective cells in Fig. 1c. Downward motions $(W<0)$ dominate in Fig. 1d.

(b) Sporadic enhancements of $\sigma^{2}$ (up to $1.0 \mathrm{~m}^{2} \mathrm{~s}^{-2}$ after 06:27 LT).

(c) AR close to $0 \mathrm{~dB}$.

In the $\mathrm{KH}$ region (2), the radar images show the following:

(a) Nearly periodic $W$ disturbances up to $+/-1.0 \mathrm{~ms}^{-1}$ around 06:00 LT, with a possible phase shift of these disturbances around $2.0 \mathrm{~km}$ from 06:05 to 06:20 LT, suggesting a critical level in accordance with the morphology of the KH braids. Such $W$ disturbances are usually met on both sides of $\mathrm{KH}$ layers (e.g., Luce et al. 2012), and they can be seen in Fig. 1c up to $2.5 \mathrm{~km}$ at least.

(b) A layer of enhanced $\sigma^{2}$ of up to $\sim 0.5 \mathrm{~m}^{2} \mathrm{~s}^{-2}$ (more persistent than in region (1)) with some local maxima coinciding with echo power maxima.

(c) AR close to $0 \mathrm{~dB}$.

These features are additional clues suggesting that the MU radar detected convective and dynamical turbulence in the regions (1) and (2), respectively.

In the stratified region (3), AR was high and $\sigma^{2}$ was small, with longer period vertical wind oscillations during UAV5, consistent with a calm, weakly turbulent region.

In summary, these characteristics confirm the intuitive interpretation of the radar echo power images of Fig. 1a, b, i.e., turbulence in convective (saturated) cells in region (1), turbulence associated with $\mathrm{KH}$ instability in region (2) and stable stratification in region (3). Incidentally, the faint blurred echoes in the range 4.2-4. 

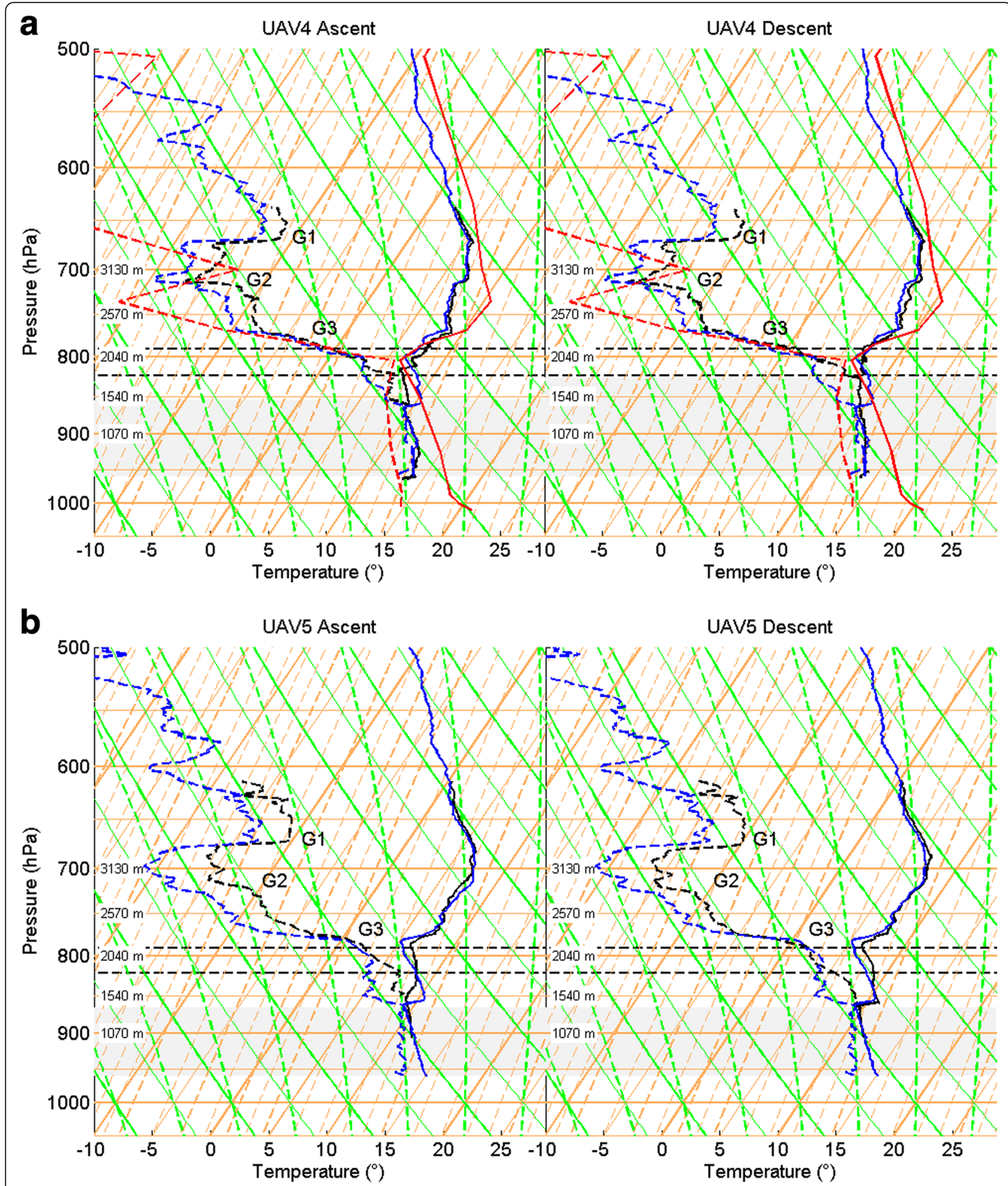

Fig. 3 a Thermodynamic diagrams showing temperature (solid lines) and dew-point temperature (dashed lines) profiles for UAV4 (black), B1 (blue), and for a balloon (red) launched on 7 June 2015 09:00 LT from Shionomisaki station, about $160 \mathrm{~km}$ south of the MU radar site. The left (right) panel shows UAV4 ascent (descent) profile. The B1 profiles are the same for both panels. The solid (dashed) green isolines show potential temperature and moist saturated potential temperature, respectively. G1, G2, and G3 refer to moisture gradients discussed in the text. The two horizontal dashed lines delineate the KH region (2) between the altitudes of 1.80 and $2.15 \mathrm{~km}$. b As Fig. 3a, but for B2 and UAV5 


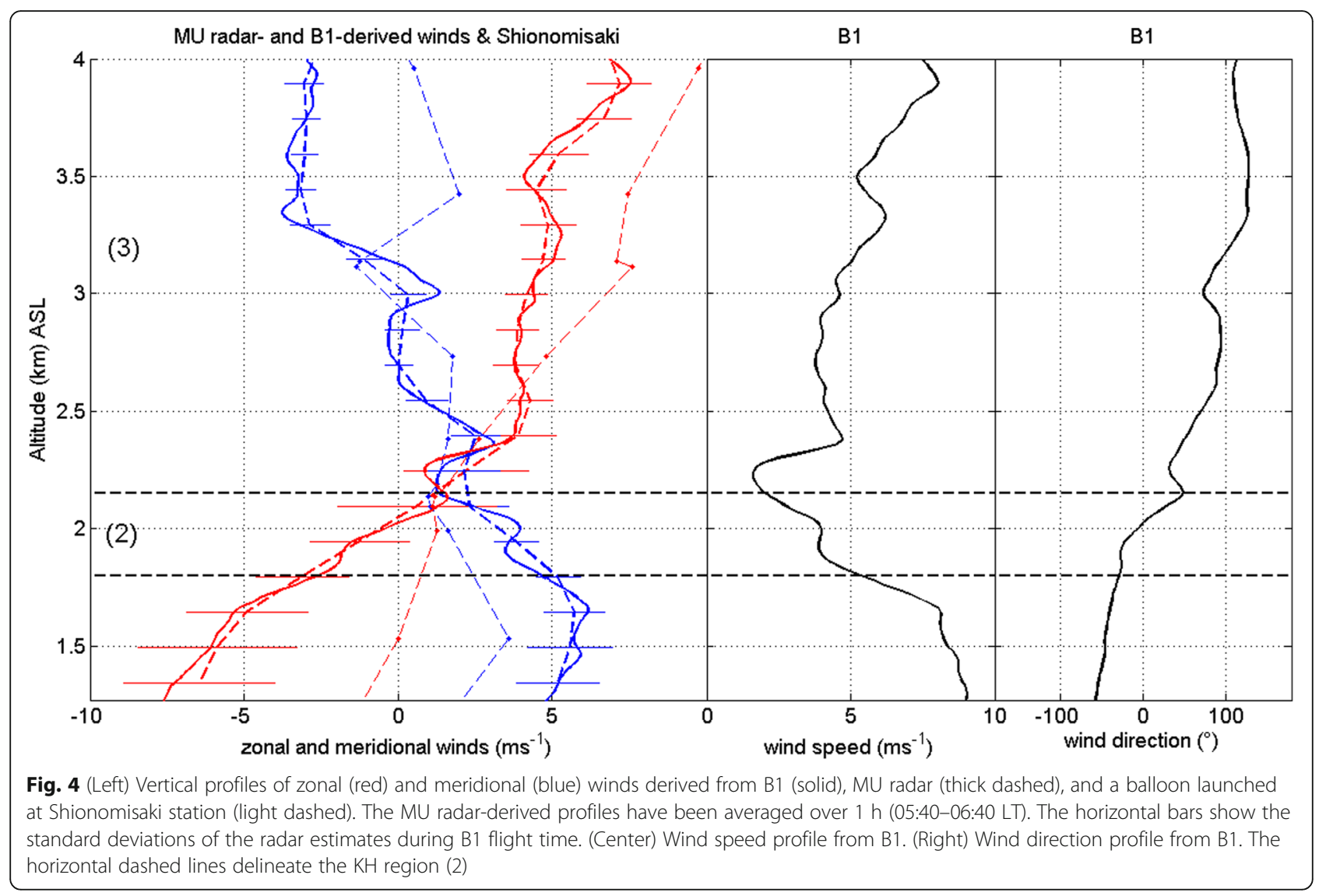

$8 \mathrm{~km}$ above region (3) in Fig. 1a and before 07:40 LT in Fig. 1b were also related to turbulence (likely another $\mathrm{KH}$ instability) as confirmed by enhanced $\sigma^{2}$ and low AR in Fig. 1c, d in the same range.

\section{Characteristics of the possible $\mathrm{KH}$ billows}

In Fig. 2, the wind shear vectors (green vectors) derived from $\mathrm{B} 1$ for the $\mathrm{KH}$ region (2) were superimposed on the balloon trajectory. The red and green vectors show the averaged wind and shear vectors, $\vec{V}$ and $\vec{S}$, respectively. The values were scaled for easy reading. Due to the wind veering, $\vec{V}$ and $\vec{S}$ were not collinear (their baselines formed an angle of $\sim 49^{\circ}$ ). The dashed lines show the possible (idealized) billow axis, expected to be perpendicular to $\vec{S}$. For the mean shear direction shown in Fig. 2, taking the wind speed $V$ equal to $4 \mathrm{~ms}^{-1}$ and $T$, the time difference between two consecutive $\mathrm{KH}$ braids observed by the MU radar equal to $330 \mathrm{~s}$ (Fig. 1a), the horizontal wavelength $\lambda$ was estimated to be $\sim 1320 \times$ $\cos \left(49^{\circ}\right) \approx 870 \mathrm{~m}$, where $1320 \mathrm{~m}$ was the apparent wavelength $(=V \times T)$. Since the amplitude A, defined as the maximum depth of the $\mathrm{KH}$ braids, was $350 \mathrm{~m}$, we have $A / \lambda=0.4$. This ratio is consistent with $0.1<A / \lambda<0.5$ reported in the literature (e.g., Fukao et al. 2011).

\section{Results of comparisons between profiles of atmospheric parameters}

Vertical profiles of temperature and dew point temperature from UAV and balloon data

The left and right panels of Fig. 3a, b shows the temperature profiles (solid black lines) and dew point temperature profiles (dashed black lines) obtained from UAV4A and D, and UAV5A and D, respectively, using a skew-T log-p emagram. Superimposed are the corresponding profiles obtained from B1 and B2 (blue lines).

On the one hand, the height variations of the two temperature profiles measured by the UAVs and balloons were very similar down to the smallest visible scales in the stably stratified region (3). The nearly constant difference (bias) between the UAV- and balloonderived dew-point temperatures should be ignored, because it was very likely due to a difference in calibration and sensitivity of the IMET and Vaisala humidity sensors when humidity was weak. Therefore, the two instruments virtually measured the same temperature profiles in region (3) despite the distance of a few $\mathrm{km}$ separating these instruments (see Fig. 2). In particular, there were noticeable humidity (and temperature) gradients, hereafter-noted G1, G2, and G3 crossed by B1, B2, UAV4, and UAV5 in region (3). "G1" and "G2" refer to 


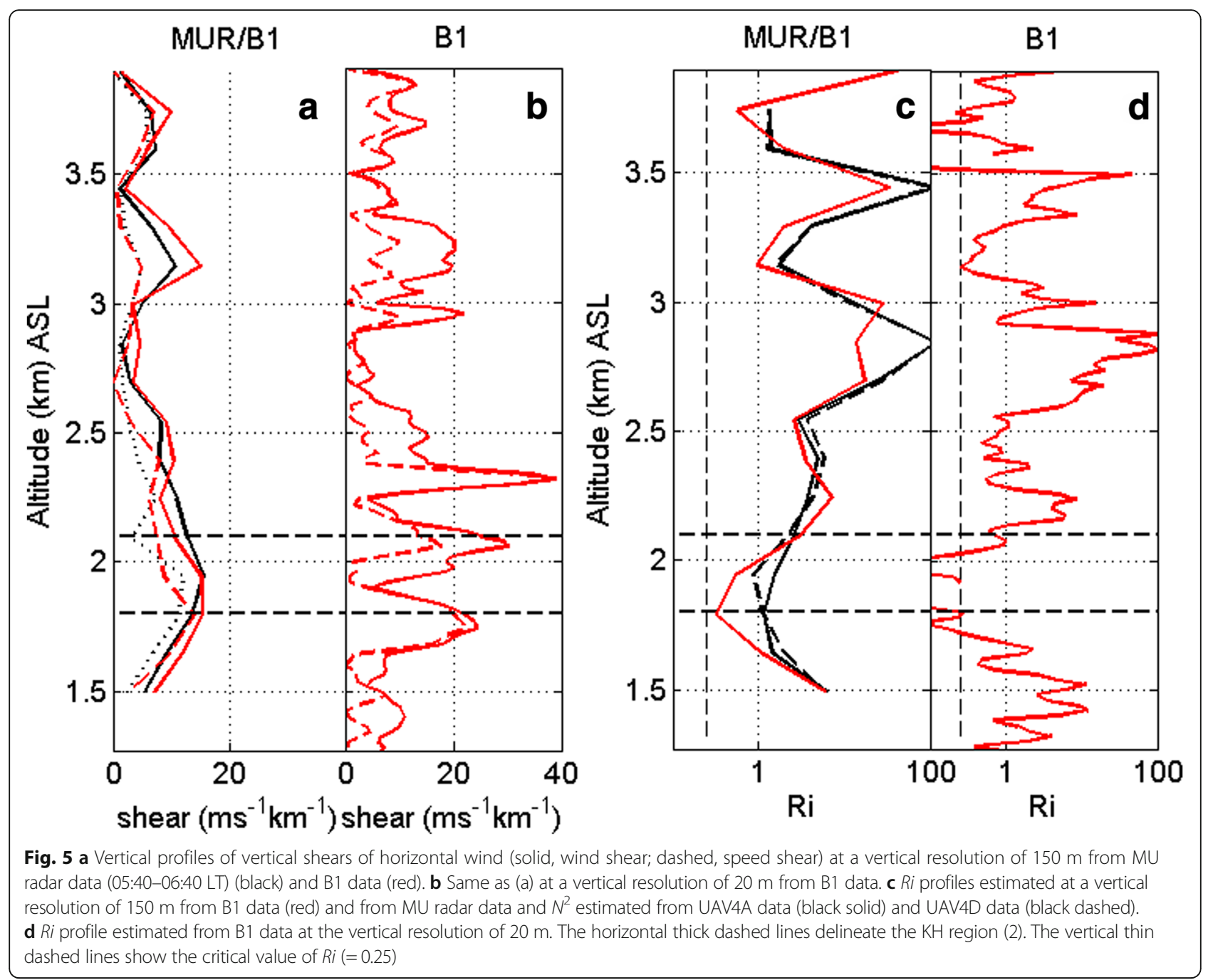

the positive and negative humidity gradients at $\sim 3.5$ and $\sim 3.0 \mathrm{~km}$, respectively. "G3" refers to the top of the humidity gradient corresponding to the capping inversion around $2.4 \mathrm{~km}$. A quantitative description will be made from comparisons of $N^{2}$ and $M^{2}$ in the section "Vertical profiles of $N^{2}$ and $M^{2}$ derived from UAV and balloon data."

On the other hand, there were significant differences between the UAV- and balloon-derived temperature profiles near the top of region (1) and in the $\mathrm{KH}$ region (2). There were nearly dry-adiabatic gradients surrounded by more or less steep temperature inversions around the $\mathrm{KH}$ region (2) in the four panels of Fig. 3, but the depth of these nearly neutral layers and the steepness of the gradients at the edges differed. These differences were by and large due to the higher horizontal and temporal variability of the fine scale structures generated by the $\mathrm{KH}$ instability and turbulence, as suggested by the radar measurements. The UAV and balloons may have crossed the $\mathrm{KH}$ billows of various depths or their remnant structures at different locations so that the vertical profiles of temperature were necessarily different.

The red curves in Fig. 3a show the temperature and dew-point temperature profiles measured by a meteorological balloon, launched on 07 June 00:00 UT (09:00 LT) from Shionomisaki station $\left(33.45^{\circ} \mathrm{N}, 135\right.$. $76^{\circ} \mathrm{E}$ ) about $160 \mathrm{~km}$ south of the MU radar site. These profiles exhibit gross features that are very similar to those revealed by the UAVs and balloons, i.e., a nearly moist (saturated) adiabatic gradient capped by a steep (negative) humidity gradient, and a temperature inversion above $800 \mathrm{hPa}(\sim 2.2-2.4 \mathrm{~km})$ and a drier layer above. Therefore, the temperature and humidity structures of the lower troposphere were likely similar over tens of kilometers at least.

\section{Vertical profiles of horizontal winds from MU radar and balloon data}

Figure 4 shows the MU radar-derived zonal and meridional wind profiles (dashed lines) averaged over 
$1 \mathrm{~h}(05: 40-06: 40 \mathrm{LT})$ around the time of B1 flight at a resolution of $150 \mathrm{~m}$. The horizontal bars indicate the variability of the wind data during the averaging time. The solid lines show the corresponding profiles measured by $\mathrm{B} 1$ at a vertical resolution of $20 \mathrm{~m}$. The radar-derived winds compared well with those measured by B1. Almost all measured values from B1 were within the interval of variability of the radar estimates, despite the better resolution of the balloon measurements. This observation indicates that the dynamical conditions met by B1 were very similar to those measured by the radar in spite of the balloon drift (see Fig. 2). The wind profiles measured by B1 show a decreasing wind speed, with wave-like disturbances below $2.15 \mathrm{~km}$ in the $\mathrm{KH}$ region (2). The wind direction was nearly constant at the bottom of the region (2), but strong veering occurred above 1.95 up to $2.15 \mathrm{~km}$ inside the region (2).

The corresponding profiles measured from Shionomisaki are also superimposed (light dashed lines). The horizontal wind profiles were also similar, despite a significantly weaker lower level jet around $1.5 \mathrm{~km}$. Therefore, the background dynamics of the lower troposphere were also similar over tens of kilometers at least, and were likely features of synoptic scale conditions.

\section{Vertical profiles of wind shear and Ri from MU radar and balloon data}

Results of comparisons between horizontal winds measured by radars and balloons have been reported many times in the literature and for a larger range in altitudes [see, e.g., Table 1 of Luce et al. 2001c]. However, to our knowledge, comparisons between wind shear and $R i$ profiles are not common, and this work constitutes the first attempt to compare two independent estimations of these parameters from the combination of UAV, balloon, and radar data.

The corresponding profiles of $S$ (red, solid) and speed shear $S_{V}$ (red, dashed) derived from B1 are shown in Fig. $5 \mathrm{~b}$. When $S \approx S_{V}$, the turning shear is negligible and the wind vector and wind shear vector directions coincide.

The profiles of $S$ and $S_{V}$ measured by B1 at a vertical resolution of $20 \mathrm{~m}$ are shown in Fig. 5b. $S$ was maximum at the bottom and top of the $\mathrm{KH}$ region (2). The wind shear was mainly a speed shear $\left(S \approx S_{V}\right)$ at the bottom and a combination of speed and turning shear at the top. B1 measured a strong speed shear $\left(\sim 40 \mathrm{~ms}^{-1} \mathrm{~km}^{-1}\right)$ at the top of the capping inversion around $2.3 \mathrm{~km}$. In the regions (1) and (3), $S$ did not locally exceed $\sim 20 \mathrm{~ms}^{-1} \mathrm{~km}^{-1}$ $\left(\sim 10 \mathrm{~ms}^{-1} \mathrm{~km}^{-1}\right.$ typically) and was mainly turning shear.

The low-resolution $(150 \mathrm{~m})$ radar- and balloon-derived profiles of shears $S$ and $S_{V}$ shown in Fig. 5a agreed well and provided consistent information on the nature of the shears. For example, both balloon- and radar-derived profiles revealed that a turning shear was dominant in the height range $3.0-3.5 \mathrm{~km}$, and a speed shear was dominant in the height range $3.5-4.0 \mathrm{~km}$. This result indicates that the dynamical conditions at vertical scale of $150 \mathrm{~m}$ were homogeneous up to the altitude of $4.0 \mathrm{~km}$, in a horizontal domain of at least $\sim 3 \mathrm{~km}$ (maximum distance of the balloon from MU radar site) and stationary (for more than $1 \mathrm{~h}$ ).

It is important to point out the substantial differences between the shear profiles at the two resolutions of 20 and $150 \mathrm{~m}$. The differences between the radar-derived shear profiles at the resolution of $150 \mathrm{~m}$ and the balloon-derived shear profiles at the resolution of $20 \mathrm{~m}$, especially below $2.3 \mathrm{~km}$, were not caused by the horizontal inhomogeneity and/or intermittency of the wind field. It was rather due to the difference of height resolution, because both profiles are similar at the resolution of $150 \mathrm{~m}$. The shear was found to be maximum at the center of the region (2) at the resolution of $150 \mathrm{~m}$, whereas it was found to be minimum, with two maxima at its edges at the resolution of $20 \mathrm{~m}$. In addition, a thin and strong speed shear layer at the altitude of $2.3 \mathrm{~km}$ and at the resolution of $20 \mathrm{~m}$ did not appear anymore at the resolution of $150 \mathrm{~m}$ in both radar- and balloon-derived profiles. At this altitude, the zonal and meridional wind profiles measured by B1 (left panel of Fig. 4) showed a clear nearly monochromatic wavy pattern, removed after applying the low-pass filtering used to get the vertical resolution of $150 \mathrm{~m}$. The contribution of these small wave disturbances was thus eliminated in the shear profiles at the resolution of $150 \mathrm{~m}$. The scale dependence of the shear profiles can have an important impact on the analysis of the dynamical background conditions. Balsley et al. (2008) pointed out the importance of the scale dependence of $R i$.

The $R i$ profile estimated from B1 data at vertical resolution of $20 \mathrm{~m}$ is shown in Fig. 5d. The profile of $N^{2}$ used for the calculations is shown by the black lines of Fig. 6a [in Fig. 6, and the subsequent figures, the label CT refers to the location of the cloud top, identified by sharp negative humidity gradients]. $R i$ was smaller than the critical value of 0.25 (and even locally negative) almost everywhere in the region (2), consistent with our expectations of a $\mathrm{KH}$ instability. $R i$ was much larger than 0.25 (up to $\sim 100$ ) almost everywhere in the stratified region (3) in accordance with the "calm" conditions of this region except above $3.5 \mathrm{~km}$, where shear-generated turbulence was also suspected. In the cloud region (1), the large values of $R i$ are not meaningful, because $N^{2}$ for subsaturated air was used and is not representative of saturated conditions.

The corresponding $R i$ profiles at low resolution $(150 \mathrm{~m})$ are shown in Fig. $5 \mathrm{c}$. The profile estimated from B1 data is shown in red. The black curves show $R i$ 

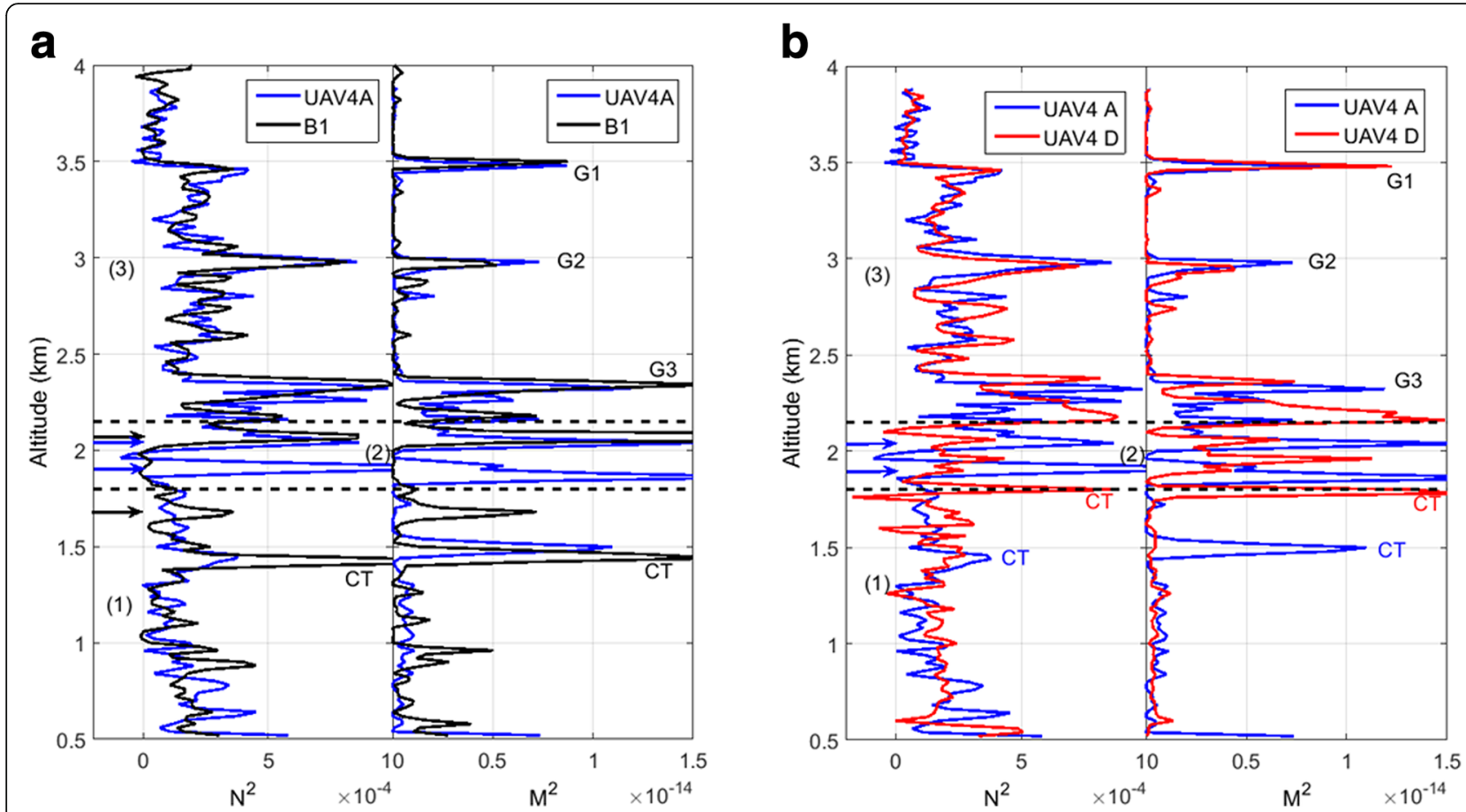

Fig. 6 a (Left) (dry) $N^{2}$ profiles at a vertical resolution of 20 m estimated from UAV4A data (blue) and B1 data (black). (Right) The corresponding $M^{2}$ profiles. The $C T$ labels refer to the $N^{2}$ and $M^{2}$ peaks in the UAV4A- and B1-derived profiles at cloud tops. The two blue (black) arrows indicate the $N^{2}$ and $M^{2}$ peaks that may coincide with the top and bottom of KH billows crossed by UAV4A (B1). The horizontal dashed lines delineate the $\mathrm{KH}$ region (2). $\mathbf{b}$ (Left) $N^{2}$ profiles estimated from UAV4A data (blue) and UAV4D data (red). (Right) The corresponding $M^{2}$ profiles. The CT labels refer to the $N^{2}$ and $M^{2}$ peaks at cloud tops that differed by about $300 \mathrm{~m}$ between ascent and descent. The two blue arrows indicate the $N^{2}$ and $M^{2}$ peaks that may coincide with the top and bottom of KH billows crossed by UAV4A. The horizontal dashed lines delineate the KH region (2)

profiles estimated independently from radar-derived shear $S$ and UAV-derived $N^{2}$ (solid, ascent; dashed, descent). The two independent $R i$ profiles agreed well confirming that the three instruments provided very reliable data at a range resolution of at least $150 \mathrm{~m}$, and the vertical structure and dynamics of the lower troposphere encountered by B1, UAV4, and MU radar were very similar at a vertical scale of $150 \mathrm{~m}$. The low-resolution profiles exhibited a minimum $(\sim 1)$ in the region (2) suggesting the possibility of $\mathrm{KH}$ instability, even if the values did not reach the critical level (0.25).

\section{Vertical profiles of $N^{2}$ and $M^{2}$ derived from UAV and balloon data}

Figures $6 \mathrm{a}$ and $7 \mathrm{a}$ show the vertical profiles of $N^{2}$ and $M^{2}$ at a vertical resolution of $20 \mathrm{~m}$ estimated from B1 and UAV4A data, and B2 and UAV5D data, respectively. For these comparisons, we selected UAV4A, because it almost coincided with B1 in time; the time difference between UAV4A and B1 did not exceed a few minutes (Fig. 1a). We selected UAV5D, closest to B2 in time. The time difference between UAV5D and B2 measurements was $\sim 40 \mathrm{~min}$ at the top and $\sim 3 \mathrm{~min}$ at the bottom (Fig. 1b).
Overall, the balloon- and UAV-derived profiles of $N^{2}$ and $M^{2}$ almost overlap everywhere. In the stratified region (3), the two instruments virtually detected the same temperature and humidity gradients with surprisingly similar intensities. In particular, the two instruments crossed practically the same gradients G1, G2, and G3 at very similar altitudes $(\sim 3.5, \sim 3.0$, and $\sim 2.3 \mathrm{~km}$, respectively). These characteristics are consistent with the persistency and steadiness of the thin echo layers monitored by the radar during the UAV flights in the stratified region (3) (Fig. 1a). Such similarities between the profiles indicate that UAVs probing the temperature and humidity fields along helical paths of $\sim 100-150 \mathrm{~m}$ in diameter provide virtually the same information as balloonborne radiosondes at vertical scales down to $20 \mathrm{~m}$ at least. These comparisons also suggest that the most prominent temperature and humidity gradients detectable at a vertical resolution of $20 \mathrm{~m}$ can persist over several hours without significant changes due to erosion processes. They can extend horizontally over a few kilometers or even a few tens of kilometers if frozenly advected, so that their aspect ratio (horizontal extent/depth) can exceed 100-1000.

There is a noticeable exception in the $\mathrm{KH}$ region (2), where two strong peaks of $N^{2}$ and $M^{2}$ were detected during 

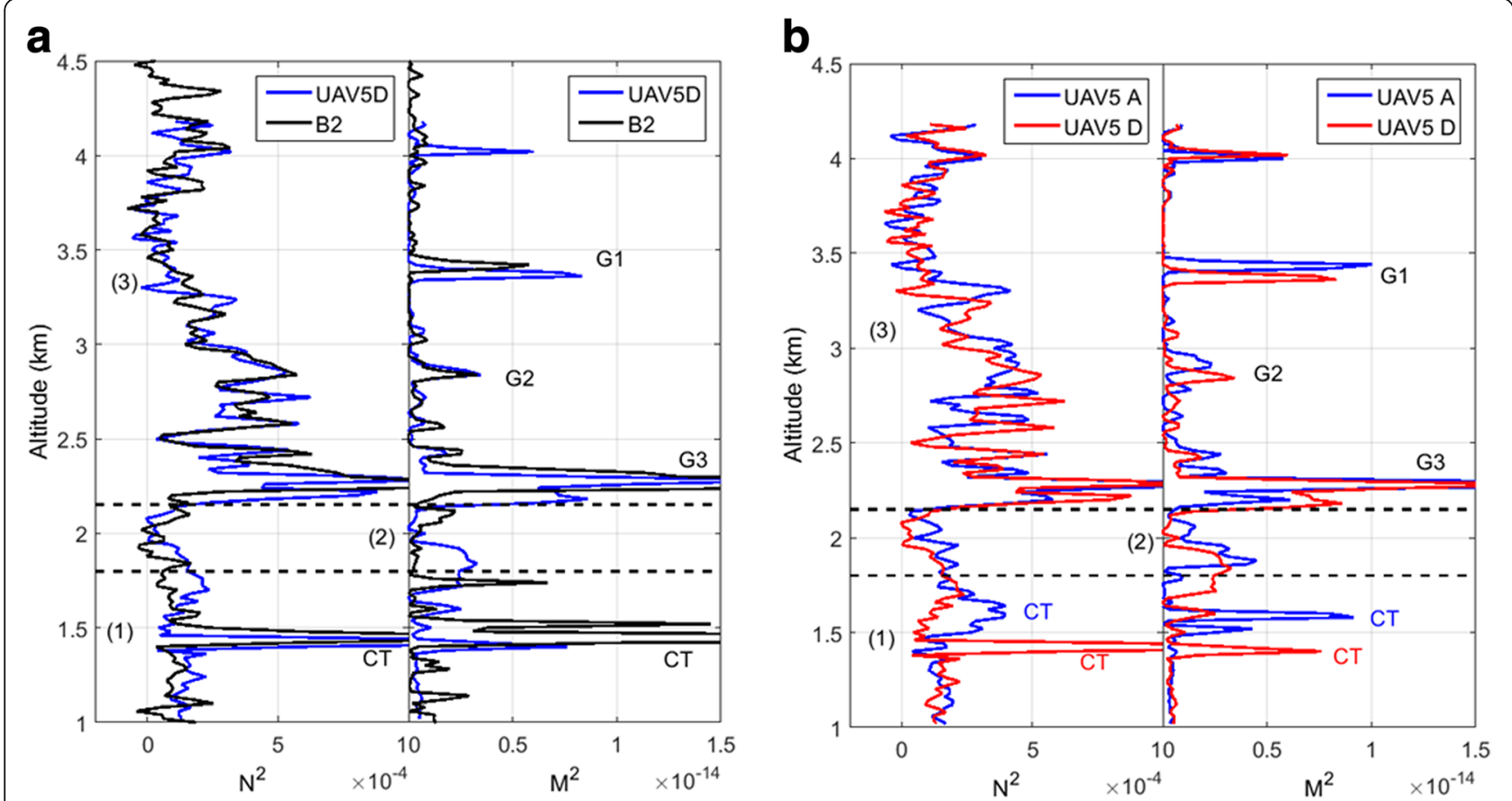

Fig. 7 a As in Fig. 6a, but for UAV5D and B2. UAV5D data are missing below $1.0 \mathrm{~km}$. b As in Fig. 6,b but for UAV5. UAV5D data are missing below $1.0 \mathrm{~km}$

UAV4A. Two blue arrows in Fig. 6a indicate these two peaks. Considering that UAV4A crossed $\mathrm{KH}$ billows according to the radar observations, they might have been the signature of the top and bottom edges of a $\mathrm{KH}$ billow, where temperature and humidity gradients should be enhanced (e.g., Woods 1968). B1 crossed the same top gradient at $\sim 2.05 \mathrm{~km}$ but not the bottom one (at $\sim 1.9 \mathrm{~km}$ ). On the one hand, because the horizontal wavelength of the $\mathrm{KH}$ billows was less than $1 \mathrm{~km}$ and the horizontal drift of the balloon exceeded $3 \mathrm{~km}$ in the $\mathrm{KH}$ region (2), B1 and UAV4A could not have crossed the same $\mathrm{KH}$ braid at the same time. The identical peaks of $N^{2}$ detected at the altitude of $2.05 \mathrm{~km}$ by $\mathrm{B} 1$ and UAV4A cannot be due to the same billow; the agreement is necessarily fortuitous but could reveal a remarkable regularity between certain characteristics of the billows. On the other hand, B1 may have crossed the bottom edge of a $\mathrm{KH}$ billow at a lower altitude $(\sim 1.65 \mathrm{~km})$, where peaks of $N^{2}$ and $M^{2}$ were detected (black arrow in Fig. 6a). This is plausible because these peaks coincided with the peak of maximum speed shear measured also by B1 (Fig. 5b). In that case, the $\mathrm{KH}$ billows detected by B1 would have been at least $150 \mathrm{~m}$ deeper than those monitored by the radar, depending on the location of $\mathrm{B} 1$ with respect to the core of the $\mathrm{KH}$ billows.

In the cloud region (1), the strong peaks of $N^{2}$ and $M^{2}$ below the altitude of $1.5 \mathrm{~km}$ in Figs. $6 \mathrm{a}$ and $7 \mathrm{a}$ were the signatures of cloud tops. They also showed a remarkable agreement in altitude.

\section{Vertical profiles of $N^{2}$ and $M^{2}$ derived from UAV data during ascents and descents}

Figures $6 \mathrm{~b}$ and $7 \mathrm{~b}$ show comparisons between the profiles of $N^{2}$ and $M^{2}$ estimated from UAV4A and D, and UAV5A and D, respectively. A close agreement was also found between the profiles. Indeed, in the stratified region (3), the profiles were virtually identical during UAV4A and D, and during UAV5A and D. However, there were slight height mismatches, in particular, between profiles collected during UAV5A and D in the height range $2.5-3.5 \mathrm{~km}$ (Fig. $7 \mathrm{~b}$ ). For example, the heights of G1 were 3.43 and $3.37 \mathrm{~km}$ during UAV5A and $\mathrm{D}$ at 07:49 and 08:01 LT, respectively, corresponding to a height offset of $-60 \mathrm{~m}$. The heights of G2 were 2.92 and $2.85 \mathrm{~km}$ during UAV5A and D at 07:45 and 08:05 LT, respectively, corresponding to a height offset of $-70 \mathrm{~m}$. These mismatches may reveal a true difference in altitude between ascent and descent, and are consistent with wave-like oscillations visible in the radar echo power image above the altitude of $2.5 \mathrm{~km}$ during UAV5 (Fig. 1b). The peaks of echo power corresponding to G1 (G2) were located at the altitudes of $3.43 \mathrm{~km}(2.93 \mathrm{~km})$ and $3.49 \mathrm{~km}(2.87 \mathrm{~km})$ during UAV5A and D, respectively, corresponding to a height offset of $-40 \mathrm{~m}$ $(-60 \mathrm{~m})$. It is very close to the values found for the peaks of $M^{2}$ (-60 and $\left.-70 \mathrm{~m}\right)$. The height agreement in the range $2.5-3.5 \mathrm{~km}$ was better between UAV5D and B2 (Fig. 7a). The height offsets for G1 and G2 
were +40 and $0 \mathrm{~m}$, respectively, with a time difference of 33 and $25 \mathrm{~min}$. The corresponding height variations of the peak of radar echo power were also weak (less than $20 \mathrm{~m}$ ) at the times of UAV5D and B2, indicating that the agreement in height between UAV5D and B2 may not have been fortuitous.

In the $\mathrm{KH}$ region (2), the $N^{2}$ and $M^{2}$ profiles significantly differed between UAV4A and D, but were very similar and showed minimum values around $2.0 \mathrm{~km}$ during UAV5A and D. An interpretation of the $N^{2}$ and $M^{2}$ profiles in the $\mathrm{KH}$ region (2) during UAV4D is difficult, because no clear and prominent structure emerged and peaks of $N^{2}$ and $M^{2}$ associated with the cloud top were located just at the bottom side of that region at $\sim 1.8 \mathrm{~km}$ (Fig. 6b). However, a careful analysis of the radar echo power image (Fig. 1a) around 06: 40 LT, when UAV5D crossed the region (2), shows that the cloud top was indeed close to $1.8 \mathrm{~km}$ and that possible smaller scale and less intense $\mathrm{KH}$ braids could be present just above (as suggested earlier). We speculate that the two $M^{2}$ peaks at the heights of $\sim 1.95$ and $\sim 2.1 \mathrm{~km}$ in the UAV4D profile (Fig. $6 \mathrm{~b}$ ) may be the signature of these smaller scale $\mathrm{KH}$ billows.

\section{Vertical profiles of $M^{2}$ derived from UAV, balloon, and radar data}

Figures 8a, b shows superimposed profiles of radarderived $M^{2}\left(M_{\text {radar }}^{2}\right)$ (black lines), UAV-derived $M^{2}\left(M_{\mathrm{UAV}}^{2}\right)$ (blue lines), and balloon-derived $M^{2}\left(M_{B}^{2}\right)$ (red lines) during UAV4A and B1 and during UAV5D and B2, respectively.

The strongest time variability of $M_{\text {radar }}^{2}$ (shown by the gray areas in Fig. 8a, b) was found in regions (1) and (2) in accordance with the more variable aspect of the echo patterns. The $M_{\mathrm{UAV} 4 \mathrm{~A}}^{2}$ and $M_{B 1}^{2}$ peaks associated with

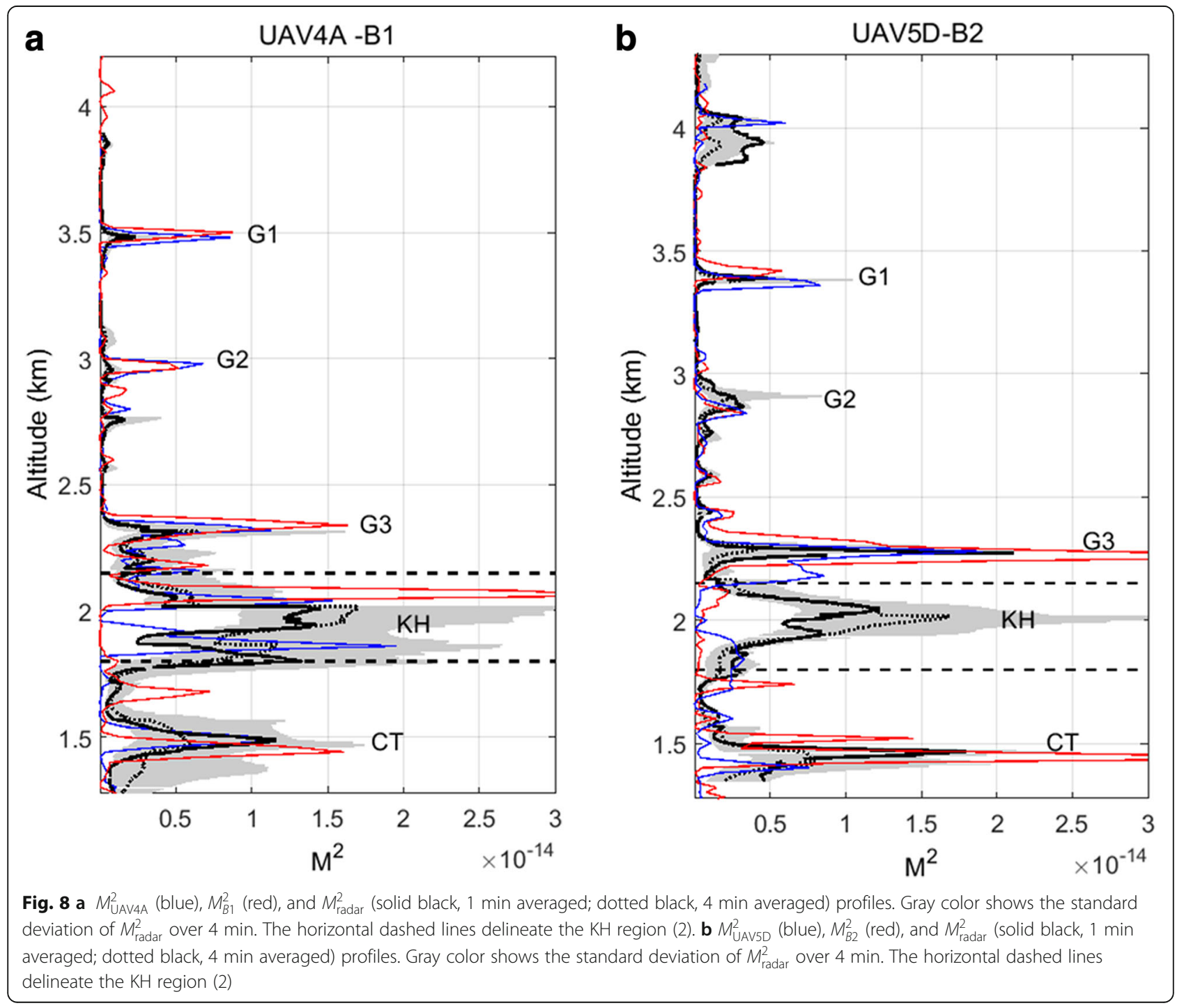


the humidity gradient at the cloud top around the height of $1.5 \mathrm{~km}$ (see Fig. 3a) coincided well with a $M_{\text {radar }}^{2}$ peak in altitude and amplitude (Fig. 8a). There was also a good agreement between the peaks at the cloud top in Fig. 8b, even though $M_{\mathrm{UAV} 5 \mathrm{D}}^{2}$ peak appeared to be weaker. This is consistent with the relatively constant altitude of the cloud top $(\sim 1.5 \mathrm{~km})$ suggested by the radar echoes in Fig. 1b. In the stratified region (3), the three main gradients G1, G2, and G3 detected by UAV4, UAV5, B1, and B2 coincided well with the strong peaks of $M_{\mathrm{radar}}^{2}$. The agreement was even better between the heights of 2.3 and $2.8 \mathrm{~km}$, where more marginal peaks were observed by all three instruments. These noticeable coincidences, already described by Luce et al. (2017) from the sole comparisons between UAV and radar measurements, confirm the ability of the MU radar to monitor and quantify decameter scale refractive index gradients in stratified conditions. The good agreements reported by Luce et al. (2017) were definitely not fortuitous, since the additional balloon data provided similar $M^{2}$ profiles as radar and UAV data, and confirmed the large horizontal extent of the temperature and humidity gradient layers at decameter scale (Fig. 3).

In the $\mathrm{KH}$ region (2), the $M_{\text {radar }}^{2}$ profile during UAV4A or B1 showed a double peak ( $\mathrm{a}$ thin peak at the height of $1.80 \mathrm{~km}$ and a broader one around the height of $2.0 \mathrm{~km}$ ) consistent with the profile obtained from UAV4A, but not exactly at the same altitude (Fig. 8)a. Therefore, the three instruments seem to have captured $\mathrm{KH}$ billows of various depths at different locations with respect to their core. In Fig. 8b, the strong enhancement of $M_{\text {radar }}^{2}$ in the core of $\mathrm{KH}$ region (2) was associated with a minimum of $M_{\mathrm{UAV} 5 \mathrm{D}}^{2}$ and $M_{B 2}^{2}$. This noticeable difference had already been noted by Luce et al. (2017) from the comparison of $M_{\text {radar }}^{2}$ and $M_{\mathrm{UAV} 5 \mathrm{D}}^{2}$, and is now confirmed from an additional and independent estimation from B2 data. Because two independent instruments (UAV and balloon) revealed $M^{2}$ minima in the same range, it is very unlikely that the differences can be explained solely by the horizontal inhomogeneity. Because the enhanced radar echo power producing the enhancements of $M^{2}$ in Fig. 8b was due to isotropic turbulence (as suggested by Fig. 1d), it is more likely that the model of $M^{2}$ comparisons (basically based on the hypothesis of specular reflection) is not appropriate for these conditions.

\section{Conclusions}

The present work was intended primarily as a demonstration of the potential offered by the combination of radar, UAV, and balloon measurements for studying the structure and dynamics of the lower troposphere down to decameter scales. We used data collected almost simultaneously by two UAVs and two balloon-borne radiosondes near the MU radar operated continuously during the ShUREX 2015 campaign. Vertical profiles of $N^{2}$ estimated from balloon and UAV data, and vertical profiles of $M^{2}$ estimated from balloon, UAV, and radar data were compared at a vertical resolution of $20 \mathrm{~m}$. In stratified conditions up to $\sim 4.0 \mathrm{~km}$, the profiles derived from the three instruments were nearly identical, with similar peaks in amplitude, position, and depth. This study constitutes a unique cross-validation of the three instruments for estimating vertical gradients of temperature, humidity, and refractive index, down to decameter scales. Even though this analysis covers only a small amount of the data collected during the ShUREX campaign, a first partial lesson is that these gradients can have horizontal extents exceeding a few kilometers at least (likely much more) with very little change in depth and strength, indicating that their generation mechanism may be related to much larger-scale processes. According to radar observations, they seemed to persist for hours with little change in echo power intensity, suggesting that turbulent diffusion was weak, in accordance with the dynamically stable conditions observed during the experiment. These properties are consistent with partial conclusions by Dalaudier et al. (1994) in the stratosphere, and Saxton et al. (1964) in the stable boundary layer. They have long been well recognized, and literature is replete with attempts at modeling their effects on radio wave propagation, for example (e.g., Gage 1990 and references therein). However, the properties of the small-scale stratification of the lower atmosphere are still poorly documented, and the use of UAV observations in combination with balloon and radar data offers new insights.

The balloon and MU radar data also provided wind and wind shear profiles so that two independent estimates of $R i$ could be obtained from additional $N^{2}$ estimated from UAV measurements at a vertical resolution of $150 \mathrm{~m}$. The two independent $R i$ profiles also showed remarkable agreement at all altitudes indicating that these $R i$ profiles were truly representative of the dynamic conditions at a vertical scale of $150 \mathrm{~m}$ in the region surrounding the MU radar, for several kilometers at least.

Large discrepancies between $N^{2}$ and $M^{2}$ profiles derived from balloon, UAV, and radar data were found in a turbulent layer generated by a Kelvin-Helmholtz shear flow instability (region 2). The causes of these discrepancies differ according to the stage of turbulence generated by $\mathrm{KH}$ instability. When coherent $\mathrm{KH}$ billows occurred (UAV4A), the differences between the various profiles of $M^{2}$ derived from the three instruments can be explained by the horizontal inhomogeneity of the refractive index field due to the limited extent of the billows (the horizontal spacing between the billows was less than $1 \mathrm{~km}$ and therefore, smaller than the horizontal separation between the instruments). When a later stage 
of turbulence was observed (UAV5), balloon- and UAVderived $M^{2}$ values were minimum, while radar-derived $M^{2}$ values were strongly enhanced. This observation, already reported by Luce et al. (2017) from UAV data only, was thus confirmed by additional balloon data. It indicates that the model used for retrieving $M^{2}$ from radar data is not suitable for the turbulent conditions met during the UAV5 flight.

\section{Appendix}

\section{Definition and estimation of $N^{2}$ and $M^{2}$}

The vertical gradient $M$ of the generalized potential refractive index is defined for non-saturated air as (Ottersten 1969):

$$
\begin{aligned}
M= & -77.6 \times 10^{-6}\left(\frac{p}{T}\right) \\
& \times\left\{\frac{N^{2}}{g}+\frac{15500 q}{T}\left[\frac{N^{2}}{g}-\left(\frac{1}{2 q}\right) \frac{d q}{d z}\right]\right\}
\end{aligned}
$$

where

$$
N^{2}=\frac{g}{T}\left(\frac{d T}{d z}+\Gamma\right)
$$

$\Gamma$, the dry adiabatic lapse rate $\left(\mathrm{km}^{-1}\right) ; T$, the temperature (K); $p$, the pressure $(\mathrm{hPa}) ; q$, the specific humidity $\left(\mathrm{gg}^{-1}\right)$; and $g$, the gravitational acceleration. In a moist lower troposphere, $M^{2}$ peaks are mainly due to moisture gradients (e.g., Tsuda et al. 1988). $N^{2}$ and $M^{2}$ profiles thus provide information on the vertical structure of the temperature and humidity fields, respectively. In the present work, the $N^{2}$ and $M^{2}$ profiles were also estimated at vertical resolution of $20 \mathrm{~m}$, because it is expected to be the very best range resolution that can be achieved by the MU radar for high signal to noise ratios in range imaging mode (e.g., Luce et al. 2018). It also minimizes the noise contribution and sensor time response effects on $N^{2}$, while keeping a good vertical resolution. Luce et al. (2017) describe the results of comparisons between UAV- and radar-derived $M^{2}$ for 7 successive UAV flights, including UAV4 and UAV5.

\section{Acknowledgements}

The authors thank JSPS for providing partial funding for the ShUREX 2015 campaign.

\section{Funding}

This work was supported by JSPS KAKENHI Grant Number JP15K13568. The $\mathrm{MU}$ radar belongs to and is operated by the Research Institute for Sustainable Humanosphere (RISH), Kyoto University.

\section{Availability of data and materials}

Made available on request from principal author.

\section{Authors' contributions}

$\mathrm{HL}$ analyzed the MU radar, balloon, and UAV data with assistance from LK, $\mathrm{HH}, \mathrm{MY}$, and $\mathrm{TT}$. LK conceived and led the campaign, and participated in analysis and synthesis of study results. DL and TM flew the UAV and collected data. All authors read and approved the final manuscript.

\section{Competing interests}

The authors declare that they have no competing interests.

\section{Publisher's Note}

Springer Nature remains neutral with regard to jurisdictional claims in published maps and institutional affiliations.

\section{Author details}

${ }^{1}$ Meditterranean Insitute of Oceanography, CNRS/INSU, UMR7294, IRD, Université de Toulon, La Garde, France. ${ }^{2}$ Research Institute for Sustainable Humanosphere, Kyoto University, Kyoto, Japan. ${ }^{3}$ Department of Aerospace Engineering Sciences, University of Colorado Boulder, Boulder, CO, USA

Received: 12 September 2017 Accepted: 3 May 2018

Published online: 01 June 2018

\section{References}

Balsley BB, Lawrence DA, Woodman RF, Fritts DC (2013) Fine-scale characteristics of temperature, wind, and turbulence in the lower atmosphere (0-1,1300 m) over the south Peruvian coast. Boundary-Layer Meteorol 147:165-178. https://doi.org/10.1007/s10546-012-9774-x

Balsley BB, Svenson G, Tjernström M (2008) On the scale-dependence of the gradient Richardson number in the residual layer. Boundary-Layer Meteorol 127:52-72. https://doi.org/10.1007/s10546-007-9251-0

Dalaudier F, Sidi C, Crochet M, Vernin J (1994) Direct evidence of sheets in the atmospheric temperature field. J Atmos Sci 51:237-248

Du Castel F (1966) Tropospheric radio wave propagation beyond the horizon. Pergamon, tarry-town, N.-Y

Fritts DC, Rastogi PK (1985) Convective and dynamical instabilities due to gravity wave motions in the lower and middle atmosphere: theory and observations. Radio Sci 20:1247-1277

Fukao S, Luce H, Mega T, Yamamoto MK (2011) Extensive studies of large-amplitude Kelvin-Helmholtz billows in the lower atmosphere with the VHF middle and upper atmosphere radar (MUR). Q J R Meteorol Soc 137:1019-1041

Fukao S, Sato T, Tsuda T, Yamamoto M, Yamanaka MD (1990) MU radar-new capabilities and system calibrations. Radio Sci 25:477-485

Gage KS (1990) In: Atlas D (ed) Radar observations of the free atmosphere: structure and dynamics, radar in meteorology, chap. 28a, pp 534-565

Gossard EE (1990) In: Atlas D (ed) Radar research on the atmospheric boundary layer, radar in meteorology, chap. 27a, pp 477-527

Gossard EE, Gaynor JE, Zamora RJ, Neff WD (1985) Fine structure of elevated stable layers observed by sounder and in situ tower sensors. J Atmos Sci 42: 2156-2169

Kantha L, Lawrence D, Luce H, Hashiguchi H, Tsuda T, Wilson R, Mixa T, Yabuki M (2017) Shigaraki UAV-radar experiment (ShUREX 2015): an overview of the campaign with some preliminary results. Prog Earth Planet Sci 4:19. https://doi.org/10.1186/s40645-017-0133-x

Lawrence DA, Balsley BB (2013) High-resolution atmospheric sensing of multiple atmospheric variables using the DataHawk small airborne measurement system. J Atmos Ocean Tech 30:2352-2366

Luce H, Crochet M, Dalaudier F (2001a) Temperature sheets and aspect sensitive radar echoes. Ann Geophys 19:899-920

Luce $H$, Crochet M, Dalaudier F, Sidi C (1995) Interpretation of VHF ST radar vertical echoes from in situ temperature sheet observations. Radio Sci 30:1002-1025

Luce H, Fukao S, Yamamoto M, Sidi C, Dalaudier F (2001c) Validation of winds measured by MU radar with GPS radiosondes during the MUTSI campaign. J Atmos Ocean Technol 18:817-829

Luce H, Hashiguchi H, Kantha L, Lawrence DA, Tsuda T, Mixa T, Yabuki M (2018) On the performance of the range imaging technique using UAVs during the ShUREX 2015 campaign. IEEE Trans Geosci Remote Sens 56:2033-2042. https://doi.org/10.1109/TGRS.2017.2772351

Luce H, Hassenpflug G, Yamamoto M, Fukao S (2006) High-resolution vertical imaging of the troposphere and lower stratosphere using the new MU radar system. Ann Geophys 24:791-805

Luce H, Kantha L, Hashiguchi H, Lawrence DA, Yabuki M, Tsuda T, Mixa T (2017) Comparisons between high-resolution profiles of squared refractive index gradient $\mathrm{M}^{2}$ measured by the MU radar and UAVs during the ShUREX 2015 campaign. Ann Geophys 35:423-441. https://doi.org/10.5194/angeo-35-423-2017

Luce H, Nishi N, Caccia JL, Fukao S, Yamamoto MK, Mega T, Hashiguchi H, Tajiri T, Nakazato M (2012) Kelvin-Helmholtz billows generated at a cirrus cloud base 
within a tropopause fold/upper-level frontal system. Geophys Res Lett 39: L04807. https://doi.org/10.1029/2011GL050120

Luce H, Takai T, Nakamura N, Yamamoto M, Fukao S (2010) Simultaneous observations of thin humidity gradients in the lower troposphere with a Raman lidar and the VHF MU radar. J Atmos Ocean Tech 27:950-956. https://doi.org/10.1175/2010JTECHA1372.1

Luce H, Yamamoto M, Fukao S, Hélal D, Crochet M (2001b) A frequency radar interferometric imaging applied with high resolution methods. J Atmos Sol Terr Phys 63:221-234

Misme P, du Castel F, Voge J (1958) Réflexions partielles dans l'atmosphère et propagation à grande distance. Première partie: Mesures météorologigues. Ann Télécom 13:209-214

Muschinski A, Wode C (1998) First in situ evidence for coexisting submeter temperature and humidity sheets in the lower free troposphere. J Atmos Sci 55:2893-2906

Ottersten H (1969) Atmospheric structure and radar backscattering in clear air. Radio Sci 4:1179-1193

Saxton JA, Lane JA, Meadows RW, Matthews RA (1964) Layer structure of the troposphere. Proc Inst Electr Eng 111:275-283

Spano E, Ghebrebhran O (1996) Complementary sequences with high sidelobe suppression factors for ST/MST radar applications. IEEE Trans Geos Rem Sens 34:317-329. https://doi.org/10.1109/36.485110

Tsuda T, May PT, Sato T, Kato S, Fukao S (1988) Simultaneous observations of reflection echoes and refractive index gradient in the troposphere and lower stratosphere. Radio Sci 23:655-665

Wilson R, Luce H, Hashiguchi H, Nishi N, Yabuki M (2014) Energetics of persistent turbulent layers underneath mid-level clouds estimated from concurrent radar and radiosonde data. J Atmos Sol Terr Phys 118:78-89

Woods JD (1968) Wave-induced shear instability in the summer thermocline. J Fluid Mech 32:791-800

Yamamoto M, Sato T, May PT, Tsuda T, Fukao S, Kato S (1988) Estimation error of spectral parameters of mesosphere-stratosphere-troposphere radars obtained by least squares fitting method and its lower bound. Radio Sci 23:1013-1021

\section{Submit your manuscript to a SpringerOpen ${ }^{\circ}$ journal and benefit from:}

- Convenient online submission

- Rigorous peer review

- Open access: articles freely available online

- High visibility within the field

- Retaining the copyright to your article

Submit your next manuscript at $\boldsymbol{s p r i n g e r o p e n . c o m ~}$ 